\title{
Ultraestructura del Inmunofenotipo CD44+/CD24- de una Línea de Células de Cáncer de Mama Triple Negativo
}

\author{
Ultrastructure of the CD44 + / CD24- Immunophenotype \\ of a Line of Triple Negative Breast Cancer Cells
}

\begin{abstract}
Fernando Riesco Vásquez ${ }^{1,2}$; Nancy Rojas Morán ${ }^{1,3}$; Nathaly Enciso Benavides ${ }^{4}$; Carlos Cisneros Huamaní3; Concepción Tejero Ortego ${ }^{4}$; Luis Alfaro Quillas ${ }^{1} \&$ Javier Enciso Gutiérrez ${ }^{1}$
\end{abstract}

RIESCO, V. F.; ROJAS, M. N.; ENCISO, B. N.; CISNEROS, H. C.; TEJERO, O. C.; ALFARO, Q. L. \& ENCISO, G. J. Ultraestructura del inmunofenotipo CD44+/CD24- de una línea de células de cáncer de mama triple negativo. Int. J. Morphol., 36(3):792-798, 2018.

RESUMEN: El cáncer de mama es la principal causa de muerte debido al cáncer en mujeres. La microscopía electrónica permite establecer características constitutivas de las células entre diferentes poblaciones celulares. Las células madre del cáncer mamario con inmunofenotipo CD44alta/CD24baja son una población de células intratumorales asociada a la quimioresistencia y metástasis, cuya ultraestructura aún no ha sido bien estudiada. El objetivo de este trabajo fue conocer características ultraestructurales de células con fenotipo de células madre del cáncer de la línea celular MDA-MB-436 de tumor mamario triple negativo comparándolas con células madre adiposas. Se utilizó microscopía electrónica de barrido y de transmisión. Previamente, mediante separación inmunomagnética positiva empleando anticuerpos anti CD44 y anti CD24 unidos a perlas magnéticas, se obtuvo una población de células con fenotipo CD44alta/CD24baja a partir de 10x106 células de la línea MDA-MB-436, la cual igual que las células madre adiposas fue cultivada en cubreobjetos para microscopía electrónica de barrido; en tanto que para microscopía electrónica de transmisión se obtuvo un pellet de células, luego se fijó con glutaraldehído al 2,5 \% y post fijó con $\mathrm{OsO}_{4} 1 \%$. Para microscopía óptica de alta resolución se usó azul de toluidina como tinción. Luego de obtener el fenotipo de células madre del cáncer se corroboró su pluripotencia detectando la expresión de los genes Oct4 y nanog mediante RT-PCR. Nuestros resultados muestran que las células de este fenotipo son pequeñas, redondeadas, recubiertas por microvellosidades abundantes pero cortas; el citoplasma tiene organelas de secreción celular y abundantes mitocondrias alargadas; el núcleo es excéntrico ocupando la mitad del volumen celular, el nucléolo es voluminoso y la heterocromatina está adosada a la membrana nuclear interna. Se concluye que el inmunofenotipo celular estudiado es una sub población celular dentro de la línea estudiada que difiere en tamaño y ultraestructura de las células madre adiposas.

PALABAS CLAVE: Células madre del cáncer; Ultraestructura; Cáncer mamario.

\section{INTRODUCCIÓN}

El cáncer de mama es la causa más común de muerte relacionada al cáncer en mujeres alrededor del mundo (International Agency for Research on Cancer, 2012). De los sub tipos de este cáncer el triple negativo comprende el $15 \%$ del cáncer de mama invasivo y generalmente es de pobre pronóstico. Mucho se ha explorado los cambios funcionales y de resistencia a drogas, mientras que los cambios estructurales a nivel celular han sido poco estudiados (AlBahlani et al., 2017).

Estudios fundacionales del siglo pasado utilizaron la microscopia electrónica para la evaluación de la ultraestructura de células cancerígenas en cultivos, así, Vic et al. (1982) analizaron el efecto del estradiol y de 2 clases de antiestrógenos en la morfología de la línea celular MCF7 de cáncer mamario humano mediante microscopia electrónica de transmisión y de barrido.

En los últimos años se han realizado estudios sobre las bases moleculares de eventos en algunos procesos de células madre del cáncer mamario mediante microscopía electrónica de transmisión (MET) (Kumar et al., 2013; Fu et al., 2014), sugiriendo utilizar nanoanticuerpos para la inmunodetección de algunos marcadores (Kijanka et al.,

\footnotetext{
${ }^{1}$ Laboratorio de Cultivo Celular e Inmunología, Universidad Científica del Sur, Lima, Perú.

${ }^{2}$ Laboratorio de Equipamiento Especializado, Facultad de Biología,Universidad Nacional Mayor de San Marcos, Lima, Perú.

${ }^{3}$ Instituto de Patología, Facultad de Medicina, Universidad Nacional Mayor de San Marcos, Lima, Perú.

${ }^{4}$ Departamento de Bioquímica y Biología Molecular IV, Facultad de Veterinaria, Universidad Complutense de Madrid, España.

Trabajo financiado por INNOVATE PERÚ mediante el convenio 378-PNICP-PIBA-2014
} 
2017). En tanto que mediante microscopía electrónica de barrido (MEB) se puede evaluar la capacidad migratoria y estrategias de migración de células cancerígenas (Bozzuto et al., 2015).

Por otro lado, se acepta que el perfil de marcadores CD44+/CD24- de células madre del cáncer (CMC) de mama, poseen mayor tumorigenicidad y potencial metastásico (AlHajj et al., 2003; Kyung-Min et al., 2016), siendo una buena opción para obtener este tipo de células, las cuales, desempeñan un importante papel en la migración de células cancerosas y la adhesión de la matriz en respuesta a un microambiente celular, mejorando así la agregación celular y el crecimiento celular (Aruffo et al. 1990).

Este trabajo es a nuestro conocimiento el primero en mostrar detalles de la estructura de las células con inmunofenotipo de células madre del cáncer mamario empleando microscopía electrónica, separadas a partir de una línea celular de tumor mamario triple negativo, y ser comparadas con células madre derivadas de tejido adiposo humano; lo que nos permitirá a futuro realizar estudios basales en ensayos de quimiosensibilidad y quimioresistencia.

\section{MATERIAL Y MÉTODO}

Línea celular. Se trabajó con la línea de célula de tumor mamario comprada de ATCC (USA) denominada MDAMB-436, la cual es del tipo triple negativo y subtipo transcripcional Claudina-baja (Heiser et al., 2012). Se cultivaron en placas de cultivo de 6 pocitos (Corning), en medio de cultivo DMEM (Sigma) suplementado con glucosa 4,5\%, L- glutamina 4 Mm, $1 \%$ de antibióticos (MerckMillipore), $1 \%$ de aminoácidos esenciales (MEM. Sigma), $10 \%$ de suero fetal bovino, insulina (Sigma) $0,01 \mathrm{mg} / \mathrm{ml} \mathrm{y}$ $16 \mathrm{mcg} / \mathrm{ml}$ de glutatión (Sigma).

Células madre adiposas humanas. Se trabajó con cultivo primario del pasaje $2-5$ de células criocongeladas a $-170{ }^{\circ} \mathrm{C}$, aisladas a partir de muestras de lipoaspirado humano, que en resumen el protocolo consistió en, someterlas a tratamiento con colagenasa tipo I $0,75 \%$, incubadas por dos horas a $37{ }^{\circ} \mathrm{C}$, luego pasadas por filtros $100 \mu \mathrm{m}$, centrifugadas a 300 g/10 minutos, las células cultivadas en placas Petri 100x20 mm (Corning), empleando medio de cultivo DMEM (Sigma), 1 \% de aminoácidos esenciales, con baja glucosa 1 $\mathrm{mg} / \mathrm{ml}$. Las células fueron expandidas en incubadora con 5 $\%$ de $\mathrm{CO}_{2}$ a $37{ }^{\circ} \mathrm{C}$ y $90 \%$ de humedad hasta que alcanzaron una confluencia de $70 \%$.

Separación magnética. La separación de células que tie- nen el fenotipo CD44alta/CD24baja, se realizó utilizando el separador MACS Separator Starting kit (Miltenyi), aplicando el protocolo de separación inmunomagnética recomendado por el fabricante del kit, que emplea perlas magnéticas marcadas con monoclonales CD44 y CD24 y columnas MS (Miltenyi).

El protocolo resumido, consiste en que luego de alcanzar el $70 \%$ de confluencia se levantaron las células con tripsina al 0,025\% para centrifugarlas a $300 \mathrm{~g}$, luego se contaron en un hemocitómetro de Neubauer, hasta conseguir una cantidad de 107 células que exige el protocolo del proveedor del kit de separación de células. Posteriormente se diluyó el sedimento celular en 80 o $40 \mathrm{ml}$ de tampón por 107 de células totales, se agregó $20 \mathrm{ml}$ de MicroBeads CD44 (Miltenyi) o $10 \mathrm{ml}$ de CD24-Biotina, se mezcló e incubó durante 15 minutos en la oscuridad a $4{ }^{\circ} \mathrm{C}$. Se lavó y centrifugó a 300 g para ser resuspendidas en $500 \mu \mathrm{l}$ de solución tampón. Para la separación positiva de células CD24+, se agregó $20 \mathrm{ml}$ de MicroBeads anti-Biotina (Miltenyi), se mezcló e incubó durante 15 minutos a $4{ }^{\circ} \mathrm{C}$. Luego en ambos casos se pasa la muestra por la columna MS (Miltenyi) adosada al separador MACS, eluyendo las células positivas luego de retirar la columna del separador recogiendo las células en un tubo de $15 \mathrm{~mL}$, para finalmente luego de centrifugar a $300 \mathrm{~g}$ sembrar el pellet de células en placas petri de $100 \times 20 \mathrm{~mm}$ y expandir a $37^{\circ} \mathrm{C}$ con $5 \%$ de $\mathrm{CO}_{2}$.

RT-PCR. Las células con inmunfenotipo CD44alta/CD24baja luego de expandirse en una placa Petri 100x20 mm se levantaron mediante un raspador de células, contadas y depositadas en un criovial con una población de $2 \times 10^{6}$ disueltas en RNAlater (Sigma) y criopreservadas a $-70^{\circ} \mathrm{C}$ hasta su procesamiento. El protocolo aplicado se basó en King (2010). Se utilizaron los primers que se describen en el Tabla I.

Microscopía electrónica: Las células con el fenotipo de células madre del cáncer mamario triple negativo para MEB se cultivaron en placas de 6 pocitos con láminas cubreobjetos pre tratadas con poly-lysina y esterilizadas con UV, en cambio para MET se trabajó con el pellet de células. Fueron cultivadas en medio de cultivo DMEM (Sigma) suplementado con suero fetal bovino $10 \%$, penicilina/estreptomicina $1 \%$.

El procedimiento para MEB en resumen consistió en que 0 los cultivos fueron fijados sobre cubre objetos, empleando una solución que contenía glutaraldehído al 2,5 $\%$ en buffer fosfato $0,1 \mathrm{M}, \mathrm{pH}$ 7,2 durante 30 minutos, luego de lavarlas con buffer fosfato para quitar el exceso de fijador fueron post fijadas con $\mathrm{OsO}_{4}$ al $1 \%$ en agua bidestilada por 1 hora en campana extractora. Luego fueron deshidratadas en una batería de alcohol etílico de grado ascendente, desde $30 \%$ hasta etanol absoluto, las muestras 
Tabla I. Primers utilizados para RT-PCR de los inmunofenotipos en estudio.
Gen Secuencia
OCT4H-F
GGAGGAAGCTGACAACAATG
OCT4H-R
CAGGCACCTCAGTTTGAATG
NANOG-F
ACT GTC TCT CCT CTT CCT TC
NANOG-R
CCTGATTGTTCCAGGATTGG
GADP HH-F
CAT CTT CCA GGA GCG AGA T
GADP HH-R

deshidratadas fueron secadas a punto crítico en un desecador modelo EMS 850 Electron Microscopy Sciences, luego recubiertas con oro (sistema de recubrimiento sputter-coater, SPI supplies), para finalmente ser examinadas y fotografiadas en un microscopio electrónico de barrido FEI Inspect $\mathrm{S} 50$ a $7.50 \mathrm{kV}$
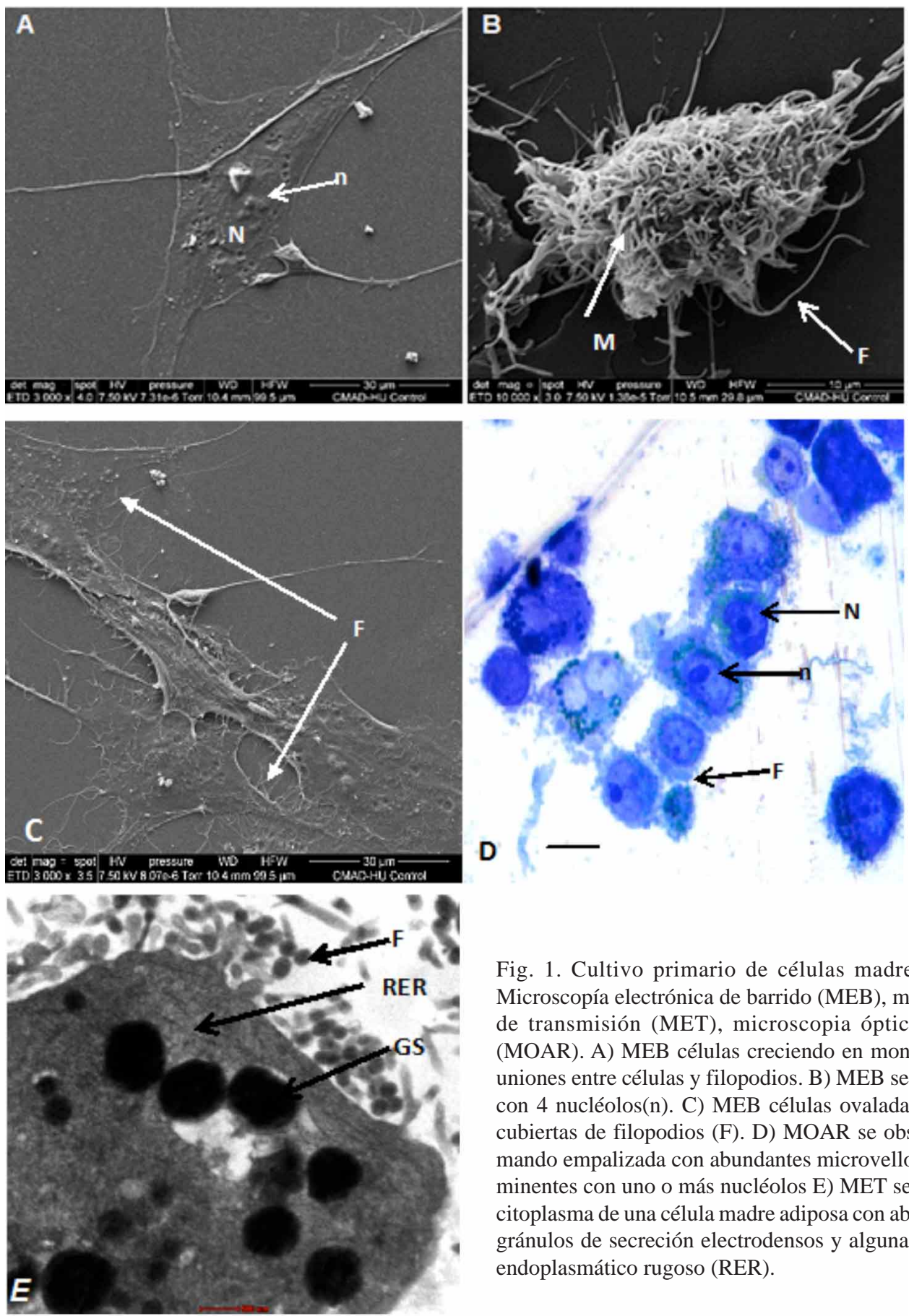

Fig. 1. Cultivo primario de células madre adiposas humanas. Microscopía electrónica de barrido (MEB), microscopía electrónica de transmisión (MET), microscopia óptica de alta resolución (MOAR). A) MEB células creciendo en monocapas se observa las uniones entre células y filopodios. B) MEB se observa el núcleo (N) con 4 nucléolos(n). C) MEB células ovaladas muy voluminosas y cubiertas de filopodios (F). D) MOAR se observan las células formando empalizada con abundantes microvellos cortos, núcleos prominentes con uno o más nucléolos E) MET se observa una zona del citoplasma de una célula madre adiposa con abundantes microvellos, gránulos de secreción electrodensos y algunas cisternas de retículo endoplasmático rugoso (RER). 
Para MET los cultivos fueron resuspendidos y concentrados por centrifugación en tubos de microcentrífuga, donde fueron fijados, lavados y post fijados como se describió para la microscopia electrónica de barrido, luego fueron deshidratados en una batería de etanol de grado ascendente, finalizando con dos pasos de acetona, la infiltración con la resina epoxi se realizó de la siguiente manera: mezcla de acetona y resina Epón-Araldita (1:1), toda la noche; Acetonaresina (1:2) 2 horas, resina pura dos horas (dos cambios). Todos Los cambios se realizaron centrifugando los tubos tres minutos antes que se cumplan los tiempos recomendados para cada paso; las muestras ya infiltradas fueron polimerizados en una estufa eléctrica a $60^{\circ} \mathrm{C}$.

Los tacos obtenidos fueron tallados y cortados en un ultramicrótomo con cuchillas de vidrio, los primeros cortes semifinos que sirvieron de guía para identificar las células de los diferentes cultivos se hicieron a $0.5 \mu \mathrm{m}$ de espesor, se recogieron en una lámina portaobjetos y fueron teñidos con azul de toluidina, estas muestras se analizaron y fotografiaron empleando la microscopía óptica de alta resolución (MOAR) que nos permite observar al detalle células y organelas de varias células a la vez, sin necesidad de coloraciones especiales bajo el microscopio de luz.

Luego de la selección de la zona a detallar, se hicieron los cortes ultrafinos que fueron recogidas en rejillas de cobre de 300mesh. Los cortes fueron impregnados con acetato de uranilo y citrato de plomo según Reynolds (1963). Estos cortes fueron analizados y fotografiados en un microscopio electrónico de transmisión Modelo Tecnai, marca FEI.

\section{RESULTADOS}

Células madre adiposas humanas. Al MEB las células cultivadas en cubreobjetos, crecen en monocapa adheridas al sustrato y entre ellas por uniones intercelulares o separadas por cortas distancias. Se caracterizan por formar colonias de células aplanadas, poligonales; algunas de superficie lisa y la mayoría con largos filopodios en los bordes celulares y microvellos muy cortas en la superficie. Estas células en su mayoría son células de $30 \mu \mathrm{m}$ de longitud (Fig. 1A y C), también se encuentran células más pequeñas de $10 \mu \mathrm{m}$ recubiertas de microvellosidades largas, ovaladas y adheridas al sustrato mediante filopodios (Fig. 1B). Al microscopio de luz con la técnica de MOAR se observan células cuyos tamaños oscilan entre 9 y $20 \mu \mathrm{m}$, en algunas zonas del campo se las observa en empalizada con su superficie celular muy vellosa, el núcleo ocupa gran volumen celular con pequeños gránulos de heterocromatina dispersos en el nucleoplasma y con dos o más nucléolos (Fig. 1C). Algunos citoplasmas contienen muchos gránulos de secreción y gotas de lípidos, esta morfología se corrobora con la MET, visualizando algunas cisternas de retículo endoplasmático rugoso (Fig. 1-D).

Células de inmunofenotipo CD 44+/CD24-. Al MEB se observa que las células en su mayoría son esféricas, forman grandes aglomeraciones de células altamente interconectadas entre ellas. Las células presentan en su superficie numerosas microvellosidades cortos, numerosos "blebs" y algunos lamelipodios y filipodios bien definidos (Figs. 2 A y B).
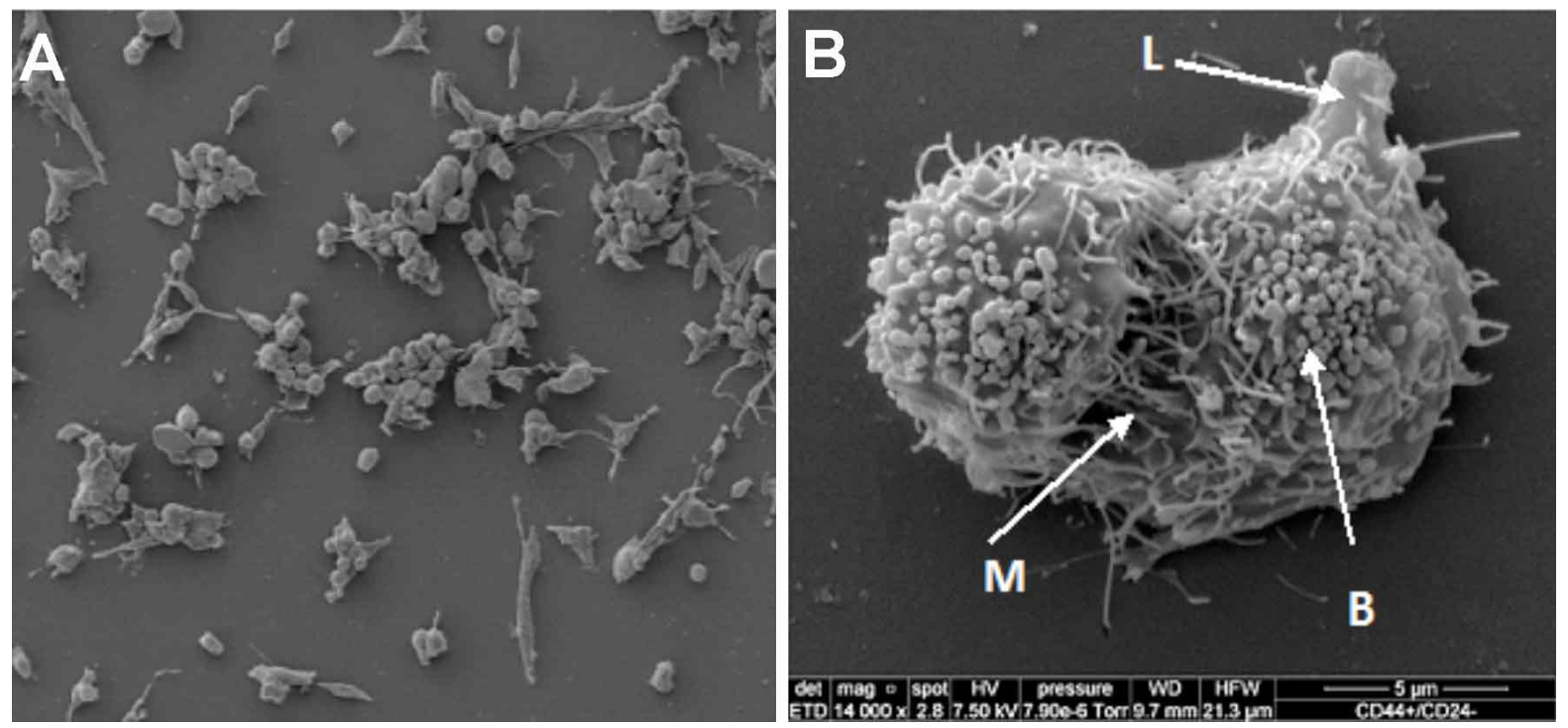

Fig. 2. Grupo de células con inmunofenotipo CD44alta/CD24baja. A) MEB Vista panorámica, se observa las células formando conglomerados. B) MEB A mayor aumento visualizamos dos células unidas, en sus superficies presentan numerosas "bleds" (B) y microvellos (M) y un lamelipodio (L). 
Mediante la técnica de microscopía óptica de alta resolución (MOAR), se ven células pequeñas, pueden llegar a medir hasta $10 \mu \mathrm{m}$. Las células tienden a ser redondeadas y tienen un núcleo excéntrico, que ocupa casi la mitad del volumen celular, tienen prominente nucléolo y la

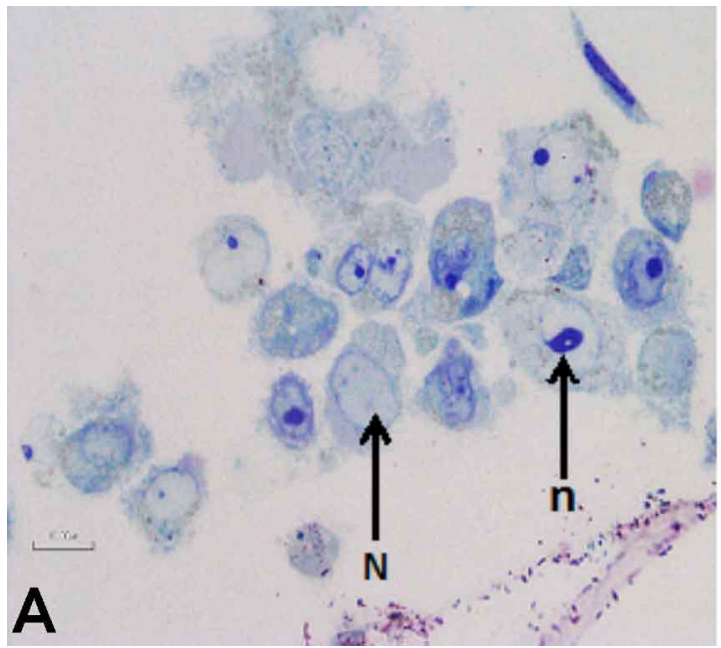

heterocromatina está adosada a la membrana nuclear interna. Los gránulos de secreción se observan en casi todas las células y en algunas son pequeños y muy densos. Toda la célula está rodeada de cortos pero abundantes microvellos (Figs. 3 A y B).

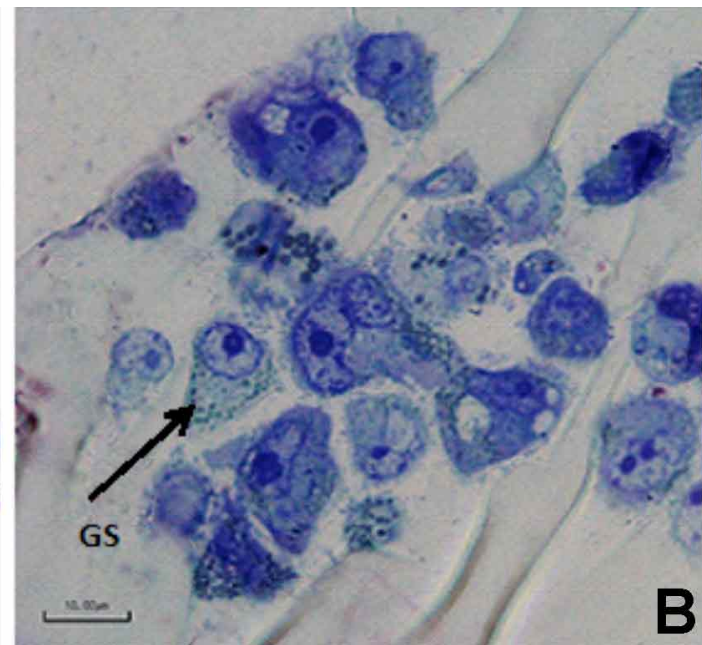

Fig. 3. Células del inmunofenotipo CD44alta/CD24baja. MOAR en (A) y (B) se observan varias células con núcleo voluminoso, con uno o más nucléolos prominentes y con pequeños gránulos de secreción.
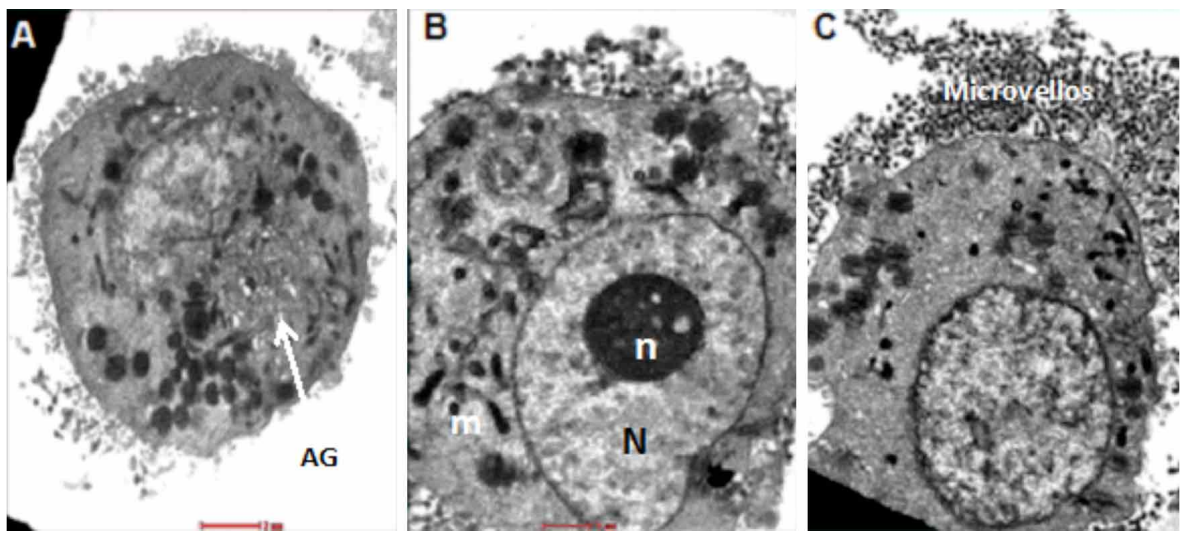

Fig. 4. Células del inmunofenotipo CD44alta/CD24baja. MET En este microscopio se visualiza la zona del Aparato de Golgi con pequeñas vesículas, mitocondrias alargadas y pequeños gránulos de secreción y rodeados de muchos microvellos cortos.

Mediante MET se confirma lo visualizado con la microscopía óptica de alta resolución Se puede observar en el citoplasma el aparato de Golgi y mitocondrias alargadas. Los gránulos de secreción son pequeños y electrodensos. Toda la célula está rodeada de cortos pero abundantes microvellos (Figs. 4 B y C).

RT-PCR: Mediante esta técnica se evidenció que las células del inmunofenotipo CD44alta/CD24baja expresaban los genes de pluripotencia Oct4 y NANOG (Fig. 5).

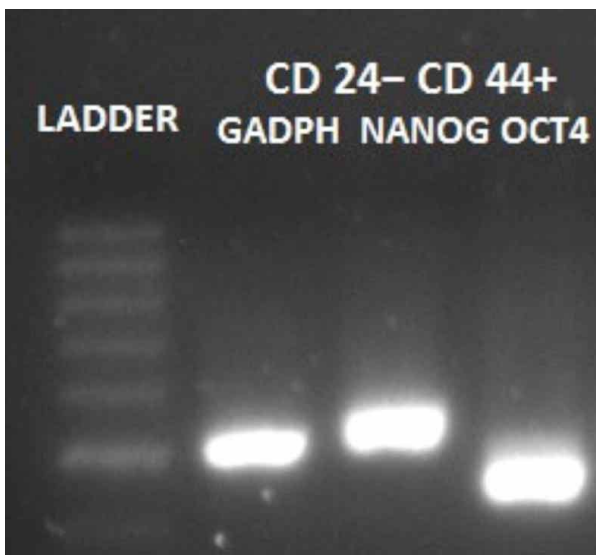

Fig. 5. RT-PCR de las células CD44alta/CD24baja para los marcadores NANOG y OCT4. 


\section{DISCUSIÓN}

Con el propósito de tener un patrón morfológico de células madre normales, estudiamos células madre adiposas de pasaje 2-5 aisladas y caracterizadas en nuestro laboratorio, las que son de tamaño heterogéneo y crecen en monocapas formando colonias separadas por distancias cortas. Similar a lo que describen otros autores, las células estudiadas en este trabajo, tienen numerosas gotas de grasa en el citoplasma, en el núcleo tienen varios nucléolos y están recubiertas por abundantes microvellosidades largas y adheridas al sustrato mediante filipodios (Miko et al., 2015), fenotipo compatible a una fase de síntesis proteica.

Por otro lado, la ultraestructura mediante microscopía electrónica de barrido de las células con inmunofenotipo de células madre del cáncer mamario triple negativo que estudiamos en este trabajo, difieren de las células madre adiposas en su tamaño pues son más pequeñas llegando hasta $10 \mu \mathrm{m}$, son esféricas con "blebs" en su superficie, se encuentran aglomeradas, altamente interconectadas entre ellas, tienen múltiples vellosidades cortas, pero poseen filipodios bien definidos similar a las CMA.

Debemos resaltar que las células con inmunofenotipo CD44alta/CD24baja estudiadas en este trabajo fueron obtenidas por inmunoselección magnética, corroborada su pluripotencia por expresar los genes Oct4 y nanog mediante RT-PCR, por la capacidad de inducir la formación de tumores en ratones con inmunosupresión química, eran células adherentes, a diferencia de otros estudios que utilizan mamoesferas en suspensión (Ghanbari et al., 2016). Este inmunofenotipo es atribuido a células madre del cáncer, las cuales se encontrarían en la cima de la organización jerárquica de la heterogeneidad del tumor (Brooks et al., 2015).

Mientras que la técnica MOAR y MET nos permitió ratificar que estas células tienden a ser esféricas, tienen un núcleo excéntrico, que ocupa casi la mitad del volumen celular, tienen prominente nucléolo y la heterocromatina está adosada a la membrana nuclear interna. En el citoplasma se observa una gran zona con organelas relacionadas con la secreción celular, aparato de Golgi y abundantes mitocondrias alargadas. Los gránulos de secreción son pequeños y electrodensos. Toda la célula está rodeada de cortos pero abundantes microvellos.

Mediante microscopia electrónica de barrido y transmisión observamos en este estudio, que las células del inmunofenotipo CD44alta/CD24baja de la línea MBA-MB436, las cuales se consideran células madre del cáncer, son en su mayoría de menor tamaño, pudiendo indicar una me- nor adhesión al sustrato lo que le permitiría una mayor capacidad de migración. El gran tamaño del núcleo y nucléolo con respecto a la célula podría explicarse por la gran cantidad de gránulos electrodensos que se encuentran dentro de las CMC y los excretados al medio externo que también se relaciona con las ampollas observadas por MEB en las células esféricas de menor tamaño.

Por haberse obtenido a partir de línea celular no conocemos la región arquitectural del tumor de donde procede, sin embargo, otros estudios han mostrado que este inmunofenotipo CD44alta/CD24baja pertenece a células mesenquimales del tumor, las cuales son primariamente quiescentes y están localizadas en el frente invasivo del tumor en tanto que las luminales son proliferativas localizadas más centralmente del tumor y tienen otro inmunofenotipo (Liu et al., 2014). Nosotros hemos mostrado en este trabajo que el linaje estudiado es adherente y por lo tanto con capacidad migratoria e invasiva, característica de las células metastásicas. Además, estudios primarios demostraron que la transición epitelial-mesenquimal, cualidad propia de las células madre, es clave en la invasión y metástasis del cáncer (Mani et al., 2008).

$\mathrm{Al}$ respecto, Jinesh et al. (2013) mostraron que las células cancerosas con características apoptóticas sobreviven al evocar un programa de emergencia, que implica la fusión de ampollas apoptóticas para formar estructuras esféricas que las llamaron ampollas-escudos (blebbishields en inglés), las células derivadas de estas, muestran heterogeneidad, propiedades de exportación de tintes, quimio resistencia y expresan marcadores de CMC. Por lo que podríamos inferir que, al tener ampollas, las células estudiadas en este trabajo confirmarían una característica más de célula madre del cáncer.

Todas estas características ultraestructurales nos llevan a concluir que las células de la línea MDA-MB-346 con inmunofenotipo de células madre del cáncer mamario triple negativo, son pequeñas, el núcleo de mayor tamaño y excéntrico, sus nucléolos son prominentes, y están recubiertas de cortos pero abundantes microvellos, características que difieren de las células madre adiposas.

RIESCO, V. F.; ROJAS, M. N.; ENCISO, B. N.; CISNEROS, H. C.; TEJERO, O. C.; ALFARO, Q. L. \& ENCISO, G. J. Ultrastructure of the CD44 + / CD24- immunophenotype of a line of triple negative breast cancer cells. Int. J. Morphol., 36(3):792798, 2018.

SUMMARY: Breast cancer is the leading cause of cancer deaths in women. Electron microscopy allows establishing constitutive characteristics of cells between different cell populations. CD44 high / CD24 low mammary cancer stem cells 
are a population of intratumoral cells associated with chemoresistance and metastasis, whose ultrastructure has not yet been well studied. The objective of this work was to know the ultrastructural characteristics of cells with cancer stem cell phenotype, of the triple negative mammary tumor cell line MDAMB-436 436 using scanning and transmission electron microscopy, and to contrast them with adipose-derived mesenchymal stem cells. Previously, by immunomagnetic purification using anti CD44 and anti CD24 antibodies bound to magnetic beads, cells populations was obtained from $10 \times 10^{6}$ cells of the MDA-MB-436 line, which, adipose-derived mesenchymal stem whereas cultivated on coverslips for scanning electron microscopy; while for transmission electron microscopy a cell pellet was obtained, then fixed with 2.5 $\%$ glutaraldehyde and post fixed with $\mathrm{OsO}_{4} 1 \%$. For high resolution optical microscopy, toluidine blue was used as staining. After obtaining the phenotype of cancer stem cells, their pluripotency was corroborated by detecting the expression of the Oct 4 and nanog genes by RT-PCR. Our results show that the cells of this phenotype are small, rounded, covered by abundant but short microvilli; the cytoplasm has organelles of cellular secretion and abundant elongated mitochondria; the nucleus is eccentric occupying half of the cellular volume, the nucleolus is bulky and the heterochromatin is attached to the inner nuclear membrane. It is concluded that the cellular immunophenotype studied is a sub-cellular population within the line studied that differs in size and ultrastructure of the adipose stem cells.

KEY WORDS: Cancer stem cells; Ultrastructure; Breast cancer.

\section{REFERENCIAS BIBLIOGRÁFICAS}

Al-Bahlani, S.; Al-Dhahli, B.; Al-Adawi, K.; Al-Nabhani, A. \& Al-Kindi M. Platinum-based drugs differentially affect the ultrastructure of breast cancer cell types. Biomed Res. Int., 2017:3178794, 2017.

Al-Hajj, M.; Wicha, M. S.; Benito-Hernandez, A.; Morrison, S. J. \& Clarke, M. F. Prospective identification of tumorigenic breast cancer cells. Proc. Nat. Acad. Sci. U. S. A., 100(7):3983-8, 2003.

Bozzuto, G.; Condello, M. \& Molinari, A. Migratory behaviour of tumour cells: a scanning electron microscopy study. Ann. Ist. Super. Sanita, 51(2):139-47, 2015

Brooks, M. D.; Burness, M. L. \& Wicha, M. S. Therapeutic implications of cellular heterogeneity and plasticity in breast cancer. Cell Stem Cell, 17(3):260-71, 2015

Fu, Y.; Chang, H.; Peng, X.; Bai, Q.; Yi, L.; Zhou, Y.; Zhu, J. \& Mi, M. Resveratrol inhibits breast cancer stem-like cells and induces autophagy via suppressing $\mathrm{Wnt} / \mathrm{b}$-catenin signaling pathway. PloS One, 9(7):e102535, 2014.

Ghanbari, T.; Azadbakht, M.; Vesi-Raygani, A. \& Khazaei, M. Isolation of breast cancer stem cell from MDA-MB231 cell line using vincristine. Int. J. Morphol., 34(4):1197-202, 2016.

Heiser, L. M.; Sadanandam, A.; Kuo, W. L.; Benz, S. C.; Goldstein, T. C.; Ng, S.; Gibb, W. J.; Wang, N. J.; Ziyad, S.; Tong, F.; Bayani, N.; Hu, Z.; Billig, J. I.; Dueregger, A.; Lewis, S.; Jakkula, L.; Korkola, J. E.; Durinck, S.; Pepin, F.; Guan, Y.; Purdom, E.; Neuvial, P.; Bengtsson, H.; Wood, K. W.; Smith, P. G.; Vassilev, L. T.; Hennessy, B. T.; Greshock, J.; Bachman, K. E.; Hardwicke, M. A.; Park, J. W.; Marton, L. J.; Wolf, D. M.; Collisson, E. A.; Neve, R. M.; Mills, G. B.; Speed, T. P.; Feiler, H. S.; Wooster, R. F.; Haussler, D.; Stuart, J. M.; Gray, J.
W. \& Spellman, P. T. Subtype and pathway specific responses to anticancer compounds in breast cancer. Proc. Natl. Acad. Sci. U. S. A., 109(8):2724-9, 2012.

International Agency for Research on Cancer (IARC). The GLOBOCAN Project. Cancer Incidence and Mortality Worldwide. Lyon, International Agency for Research on Cancer (IARC), 2012. Disponible en: http:// globocan.iarc.fr

Jinesh, G. G.; Choi, W.; Shah, J. B.; Lee, E. K.; Willis, D. L. \& Kamat, A. M. Blebbishields, the emergency program for cancer stem cells: sphere formation and tumorigenesis after apoptosis. Cell Death Differ., 20(3):382-95, 2013.

Kijanka, M.; van Donselaar, E. G.; Müller, W. H.; Dorresteijn, B.; PopovCeleketic, D.; El Khattabi, M.; Verrips, C. T.; van Bergen En Henegouwen, P. M. P. \& Post, J. A. A novel immuno-gold labeling protocol for nanobody-based detection of HER2 in breast cancer cells using immuno-electron microscopy. J. Struct. Biol., 199(1):1-11, 2017.

King, N. (Ed.). RT-PCR Protocols. $2^{\text {nd }}$ ed. Heidelberg, Springer, 2010.

Kumar, D.; Shankar, S. \& Srivastava, R. K. Rottlerin-induced autophagy leads to the apoptosis in breast cancer stem cells: molecular mechanisms. Mol. Cancer, 12(1):171, 2013.

Lee, K. M.; Lee, M.; Lee, J.; Kim, S. W.; Moon, H. G.; Noh, D. Y. \& Han, W. Enhanced anti-tumor activity and cytotoxic effect on cancer stem cell population of metformin-butyrate compared with metformin $\mathrm{HCl}$ in breast cancer. Oncotarget, 7(25):38500-12, 2016.

Liu, S.; Cong, Y.; Wang, D.; Sun, Y.; Deng, L.; Liu, Y.; Martin-Trevino, R.; Shang, L.; McDermott, S. P.; Landis, M. D.; Hong, S.; Adams, A.; D'Angelo, R.; Ginestier, C.; Charafe-Jauffret, E.; Clouthier, S. G.; Birnbaum, D.; Wong, S. T.; Zhan, M.; Chang, J. C. \& Wicha, M. S. Breastcancer stem cells transition between epithelial and mesenchymal states reflective of their normal counterparts. Stem Cell Rep., 2(1):7891, 2014.

Mani, S. A.; Guo, W.; Liao, M. J.; Eaton, E. N.; Ayyanan, A.; Zhou, A. Y.; Brooks, M.; Reinhard, F.; Zhang, C. C.; Shipitsin, M.; Campbell, L. L.; Polyak, K.; Brisken, C.; Yang, J. \& Weinberg, R. A. The epithelialmesenchymal transition generates cells with properties of stem cells. Cell, 133(4):704-15, 2008.

Miko, M.; Danisovic, L.; Majidi, A. \& Varga, I. Ultrastructural analysis of different human mesenchymal stem cells after in vitro expansion: a technical review. Eur. J. Histochem., 59(4):2528, 2015.

Reynolds, E. S. The use of lead citrate at high $\mathrm{pH}$ as an electron-opaque stain in electron microscopy. J. Cell Biol., 17:208-12, 1963.

Vic, P.; Vignon, F.; Derocq, D. \& Rochefort, H. Effect of estradiol on the ultrastructure of the MCF7 human breast cancer cells in culture. Cancer Res., 42(2):667-73, 1982.

Dirección para correspondencia:

Javier Enciso Gutiérrez, MV; MSc

Jefe del Laboratorio de Cultivo Celular

Universidad Científica del Sur

Lima

PERÚ

Email:jenciso333@yahoo.com.mx

Recibido :20-12-2017

Aceptado:23-03-2018 